\title{
Active Components from Lagotis Brachystachya Maintain Uric Acid Homeostasis by Inhibiting Renal TLR4-NLRP3 Signaling in Hyperuricemic Mice
}

\section{Ji-Xiao Zhu}

Jiangxi University of Traditional Chinese Medicine

Hai-Yan Yang

Jiangxi University of Traditional Chinese Medicine

Wei-Qiong Hu

Jiangxi University of Traditional Chinese Medicine

Jie Cheng

Huaqiao University College of Chemical Engineering

\section{Yang Liu}

Jiangxi University of Traditional Chinese Medicine

\section{Li-Tao Yi}

Huaqiao University College of Chemical Engineering

Hong-Yu Cheng ( $\nabla 5441626 @ q q . c o m)$

Jiangxi University of Traditional Chinese Medicine https://orcid.org/0000-0003-1619-4308

\section{Research Article}

Keywords: Luteolin, Luteoloside, Apigenin, Hyperuricemia, Uric acid transporter, Inflammation

Posted Date: March 12th, 2021

DOl: https://doi.org/10.21203/rs.3.rs-283474/v1

License: (9) This work is licensed under a Creative Commons Attribution 4.0 International License.

Read Full License

Version of Record: A version of this preprint was published at Inflammopharmacology on July 9th, 2021. See the published version at https://doi.org/10.1007/s10787-021-00844-5. 


\section{Abstract}

Lagotis brachystachya Maxim is an herb widely used in traditional Tibet medicine. Our previous study indicated that total extracts from Lagotis brachystachya could lower uric acid levels. This study aimed to further elucidate the active components (luteolin, luteoloside and apigenin) isolated from Lagotis brachystachya and the underlying mechanism in vitro and vivo. The results showed that treatment with luteolin and luteoloside reversed the reduction of organic anion transporter 1 (OAT1) levels, while apigenin attenuated the elevation of urate transporter 1 (URAT1) and glucose transporter 9 (GLUT9) levels in uric acid-treated HK-2 cells, which were consistent with the finding in the kidney of potassium oxonate (PO)-induced mice. On the other hand, hepatic xanthine oxidase activity was inhibited by the components. In addition, all of these active components improved the morphology of the kidney in hyperuricemic mice. Moreover, molecular docking showed that luteolin, luteoloside and apigenin could bind TLR4 and NLRP3. Consistently, western blot showed that the components inhibited TLR4/MyD88/NLRP3 signaling. In conclusion, these results indicated that luteolin, luteoloside and apigenin could attenuate hyperuricemia by decreasing the production and increasing the excretion of uric acid, which were mediated by the inhibition of inflammatory signaling pathways.

\section{Introduction}

Hyperuricemia is a metabolic disease that causes increased production or decreased metabolism of uric acid (Shekelle et al., 2017). The abnormality of either production or excretion leads to a high concentration of uric acid. If uric acid maintains high concentration for a period of time, hyperuricemia enters gout's acute course. The transportation of uric acid in the kidney depends on the transport proteins in renal tubular epithelial cells. It is now clear that there are three transporters involved in the transport of urate in proximal convoluted tubule, organic anion transporter (OAT1), urate anion transporter 1 (URAT1) and glucose transporter 9 (GLUT9) (Xu et al., 2017). OAT1 is a crucial transporter of OATs family that is mainly responsible for the process of renal uric acid excretion (Azevedo et al., 2019). It uptakes urate from blood and secretes it into tubular cells. In addition, uric acid is reabsorbed by URAT1 in the renal tubule apical membrane and then transported from the renal tubular lumen to the renal tubular epithelial cells. During this process, the blood uric acid levels are maintained. Clinically available drugs such as benzbromarone and probenecid are effective inhibitors of URAT1, which inhibited the process of reabsorption to promote uric acid excretion (Dong et al., 2019). Similar to the function of URAT1, GLUT9 is also an important transporter in the reabsorption of urate in the proximal membrane (Zhang et al., 2016). Therefore, these three transport proteins are responsible for uric acid reabsorption and secretion in the kidney.

Besides the function of transport proteins, inflammation is considered to be involved in the pathophysiology of hyperuricemia. High uric acid has been shown to activate the TLR4/NLRP3 pathway and its related caspase-1 expression and the release of interleukin $1 \beta$ (IL-1 $\beta$ ) (Ma et al., 2020; Romero et al., 2017). Typically, TLR4 stimulates the NF-KB pathway to modulate the inflammation-related genes and the secretion of pro-inflammatory cytokines, IL-1 $\beta$, IL-6, and tumor necrosis factor- $\alpha$ (TNF- $\alpha$ ). There was 
evidence that activated NF-KB phosphorylation was activated in both primary renal proximal tubule cells and mice induced by uric acid (De Nardo and Latz, 2011; Wang et al., 2018). Meanwhile, NLRP3 is responsible for the process of pro-IL-1 $\beta$ to mature IL-1 $\beta$.

Lagotis brachystachys Maxim is a traditional Tibetan medicine. It is primarily used to alleviate inflammation in local Tibet. Our previous study showed that the total ethanolic extract of Lagotis brachystachys could reduce serum uric acid levels in hyperuricemia mice, which might be induced by the active components from the flavonoid fraction (Xiong et al., 2018). Subsequently, three active components including luteolin, luteoloside and apigenin were separated from the flavonoid fraction of Lagotis brachystachy (Zhu et al., 2019). In the present study, the effects of luteolin, luteoloside and apigenin against hyperuricemia were firstly evaluated in vitro and in vivo. Furthermore, considering that flavonoids are expected to ameliorate the inflammatory symptoms in autoinflammatory diseases associated with NLRP3 inflammasome activation (Lim et al., 2018), TLR4/NLRP3 underlying mechanism was also investigated in mice with potassium oxonate (PO)-induced hyperuricemia.

\section{Materials And Methods}

\section{Animals}

Six-weeks old male Kunming mice $(22 \pm 2 \mathrm{~g}$ ) were purchased from Animal center of Jiangxi University of Traditional Chinese Medicine, PR China. Animals were housed five per cage $(320 \times 180 \times 160 \mathrm{~cm})$ under a normal 12-h/12-h light/dark schedule (lights on at 07:00 a.m) during the experiments. The animals were allowed one week to adapt before the beginning of the experiments. Ambient temperature and relative humidity were maintained at $22 \pm 2^{\circ} \mathrm{C}$ and $55 \pm 5 \%$. Animals have free access to food and water.

The animal experiments complied with the ARRIVE guidelines and were approved by the Jiangxi University of Traditional Chinese Medicine.

All procedures were performed following the published guidelines of the China Council on Animal Care.

\section{Reagents}

Uric acid, benzbromarone, allopurinol and PO were purchased from Sigma (St. Louis, USA). Elisa kits for IL-1 $\beta$ and TNF-a were purchased from Xinbosheng (Shenzhen, China). Anti-GLUT9, anti-TLR4 and antiNLPR3 antibodies were purchased from Bioss (Beijing, China). Anti-OAT1, anti- $\beta$-actin, anti-URAT1, antiAnti-MyD88 and anti-IL-1 $\beta$ antibodies were purchased from Proteintech (Chicago, USA). Xanthine oxidase, urea nitrogen and adenosine deaminase kits were purchased from Jiancheng (Nanjing, China).

\section{Isolation of luteolin, luteoloside and apigenin from Lagotis brachystachys}

Lagotis brachystachya Maxim which was collected from the Sichuan Province of China in 2015 was identified by Professor Guo-Yue Zhong (Jiangxi University of Traditional Chinese Medicine). A voucher specimen (No.01-03-23-15) is deposited at the research center. The dried Lagotis brachystachya was 
extract with 5 times $70 \%$ ethanol at $60^{\circ} \mathrm{C}$ for $2 \mathrm{~h}$. The process was repeated for twice and the total extracts were concentrated under reduced pressure. Then the ethanol extract was passed over a porous poly mergel D101 column $(20 \times 150 \mathrm{~cm})$. After washed with $\mathrm{H}_{2} \mathrm{O}$, the extracts were eluted with a stepwise gradient of $\mathrm{MeOH}-\mathrm{H}_{2} \mathrm{O}(3: 7,6: 4,1: 0)$. The $\mathrm{MeOH}-\mathrm{H}_{2} \mathrm{O}$ (3:7) eluate was subsequently chromatographed on a silica gel column $\left(9 \times 60 \mathrm{~cm}, 200-300\right.$ mesh) and eluted with $\mathrm{CH}_{2} \mathrm{Cl}_{2}-\mathrm{CH}_{3} \mathrm{OH}(100: 2,100: 4,100: 6$, 100:8), and then eluted by ODS column chromatography gradient and repeated recrystallization to obtain the active compounds. ${ }^{1} \mathrm{H}$ and ${ }^{13} \mathrm{C}$ NMR spectroscopic analysis were performed to confirm the structures of active compounds as luteolin, luteoloside and apigenin, respectively (Fig. 1).

\section{Molecular docking}

The crystal structure of the TLR4-MD2 complex and NLRP3 were derived from the RCSB Protein Data Bank (http://www.rcsb.org/). TLR4 complex (PDB code, 3FXI), NLRP3 (PDB code, 6NPY), luteolin, luteoloside and apigenin were processed by Pymol and then calculated by AutoDock Vina. LigPlus was used for interaction analysis.

\section{Measurement of HK-2 cell viability}

The 3rd generation of HK-2 cells was incubated in 96-well plate $\left(5.5 \times 10^{3} / \mathrm{mL}\right.$ for each well). After culturing for 24 hours, medium containing different concentrations of reagents was added as following: uric acid $(50,100,200,400,800 \mu \mathrm{M} / \mathrm{L})$, benzbromarone $(25,50,100 \mu \mathrm{M} / \mathrm{L})$, luteolin $(3.125,6.25,12.5,25$, $50,100 \mu \mathrm{M} / \mathrm{L})$, luteoloside $(3.125,6.25,12.5,25,50,100 \mu \mathrm{M} / \mathrm{L})$ and apigenin $(3.125,6.25,12.5,25,50$, $100 \mu \mathrm{M} / \mathrm{L}$ ). Forty-eight hours later, the medium is removed, and $50 \mu \mathrm{L}$ of $10 \%$ TCA was added to each well. Then the plate was transferred to a $4^{\circ} \mathrm{C}$ refrigerator for fixing with 1 hour. After removing the solution and drying, $50 \mu \mathrm{L} 0.4 \%$ SRB dye was added and incubated for $30 \mathrm{~min}$. $1 \%$ of acetic acid was subsequently used to rinse the cells. Finally, $100 \mu \mathrm{L}$ Tris-base lye was added and measured with a microplate reader at $515 \mathrm{~nm}$.

\section{Treatment in vitro}

Blank experiment. The third-generation HK-2 cells were randomly divided into a control group, a positive drug group $(25 \mu \mathrm{mol} / \mathrm{L}$ benzbromarone), two luteolin groups $(3.125,6.25 \mu \mathrm{mol} / \mathrm{L})$, two luteoloside groups $(3.125,6.25 \mu \mathrm{mol} / \mathrm{L})$ and two apigenin groups $(3.125,6.25 \mu \mathrm{mol} / \mathrm{L})$.

Intervention experiment. The third-generation HK-2 cells were randomly divided into a control group, a uric acid group, a positive drug group ( $25 \mu \mathrm{mol} / \mathrm{L}$ benzbromarone), two luteolin groups $(3.125,6.25 \mu \mathrm{mol} / \mathrm{L})$, two luteoloside groups $(3.125,6.25 \mu \mathrm{mol} / \mathrm{L})$ and two apigenin groups $(3.125,6.25 \mu \mathrm{mol} / \mathrm{L})$. All groups except control group were treated with $400 \mu \mathrm{mol} / \mathrm{L}$ uric acid.

All the groups were treated and incubated for 48 hours, followed by collection.

\section{Drug treatment in vivo}


90 mice were randomly divided into 9 groups as following: Control-vehicle group, PO-vehicle group, POallopurinol group (10mg/kg), PO-luteolin groups (20,50mg/kg), PO-luteoloside (20,50mg/kg), POapigenin $(20,50 \mathrm{mg} / \mathrm{kg})$. Drugs or vehicle were orally continuous administration once a day for 7 days. On the seventh day, $\mathrm{PO}(350 \mathrm{mg} / \mathrm{kg})$ was intraperitoneal injected 1 hour prior to drug administration. One hour after the last drug administration, blood was collected to obtain the serum. The liver and kidney in one side of the mouse were dissected extracted in liquid nitrogen, and stored at later. The kidney from the other side of the mouse was fixed in $4 \%$ paraformaldehyde solution.

\section{ELISA analysis}

Serum uric acid, urea nitrogen, adenosine deaminase, IL-1 $\beta$, TNF-a levels, and hepatic xanthine oxidase levels were measured based on the manufacturer's instruction of the kits.

\section{Histopathological examination}

The kidney tissue was cut into pieces after fixing in $4 \%$ paraformaldehyde. The tissue then was placed in an embedding box and rinsed, followed by dehydration with $50 \%$ ethanol for $30 \mathrm{~min}, 70 \%$ ethanol for $30 \mathrm{~min}, 80 \%$ ethanol for $30 \mathrm{~min}, 90 \%$ ethanol for $20 \mathrm{~min}, 90 \%$ ethanol for $20 \mathrm{~min}$, ethanol for $10 \mathrm{~min}$, ethanol for $10 \mathrm{~min}$, xylene for $5 \mathrm{~min}$, xylene for $5 \mathrm{~min}$, paraffin for $30 \mathrm{~min}$, paraffin for $30 \mathrm{~min}$. After embedding, the tissue was cut into a slice $(4 \mu \mathrm{m})$. After incubated in the oven for $2 \mathrm{~h}$, the slices were dewaxed as following: xylene for $10 \mathrm{~min}$, xylene for $10 \mathrm{~min}$, ethanol for $5 \mathrm{~min}, 95 \%$ ethanol for $2 \mathrm{~min}, 80 \%$ ethanol for $2 \mathrm{~min}, 70 \%$ ethanol for $2 \mathrm{~min}$ and distilled water for $2 \mathrm{~min}$. Subsequently, the slices were placed in hematoxylin staining solution for $8 \mathrm{~min}$ and eosin staining solution for $30 \mathrm{sec}$. Finally, the slices were sealed and observed under a microscope.

\section{Western blot}

Cells, kidney and liver tissues were homogenized with lysis buffer. The homogenates were centrifuged at $12000 \times \mathrm{g}$ for $15 \mathrm{~min}$ at $4^{\circ} \mathrm{C}$. The supernatant was collected and used for protein determination by the BCA method. The proteins were separated in SDS-PAGE electrophoresis (80V in concentration gel; $120 \mathrm{~V}$ in separation gel). Then the gel was transferred to the PVDF membrane. After the transfer process, PVDF membrane was incubated in blocking solution for $2 \mathrm{~h}$ followed by primary antibodies at $4^{\circ} \mathrm{C}$ for $12 \mathrm{~h}$ (GLUT9, 1:5000; URAT1, 1 :2000; OAT1, 1: 2000; TLR4, 1: 2000; NLRP3, 1: 2000; MyD88, 1: 2000; IL-1ß, 1: $2000 ; \beta$-actin 1:4000). After washing with TBST, the membrane was incubated with a secondary antibody. Finally, the membrane was exposed with ECL luminescent solution. The image was collected with a gel image analyzer. Image $\mathrm{J}$ was used to analyze the gray value of the bands.

\section{Statistical analyses}

The data are expressed as means \pm SD. The data were and analyzed by One-way ANOVA followed by Tukey post-hoc test in Graphpad Prism. $P<0.05$ is considered as a significant difference.

\section{Results}




\section{The effects of uric acid and active components on HK-2 cell viability}

As shown in Fig. $2 \mathrm{~A}$, there is a negative correlation between uric acid concentration and HK-2 cell viability as with the increase of uric acid concentration, HK-2 cell viability decreased [ $<<0.01]$. When the uric acid reached $400 \mu \mathrm{mol} / \mathrm{L}, \mathrm{HK}-2$ cell viability was declined to about $50 \%$. Therefore, $400 \mu \mathrm{mol} / \mathrm{L}$ uric acid was used to induce cell damage by hyperuricemia in HK-2 cells in the following experiment. In addition, as shown in Fig. 2B-E, compared with the control group, benzbromarone at $25 \mu \mathrm{mol} / \mathrm{L}$, active components (luteolin, luteoloside and apigenin) at 3.125 and $6.25 \mu \mathrm{mol} / \mathrm{L}$ did not affect HK-2 cell viability. In this respect, $25 \mu \mathrm{mol} / \mathrm{L}$ benzbromarone as well as 3.125 and $6.25 \mu \mathrm{mol} / \mathrm{L}$ active components were used for the following experiment.

\section{Effects of active components on the levels of GLUT9, URAT1 and OAT1 in normal HK-2 cells}

The effects of luteolin, luteoloside and apigenin on GLUT9, URAT1 and OAT1 levels in normal HK-2 cells were shown in Fig. 3. One-way ANOVA indicated the effect of treatment on GLUT9[p $<0.01]$, URAT1 [ $p<$ $0.01]$ or OAT1 [ $<0.01]$ levels was significant. Compared with the vehicle group, benzbromarone decreased URAT1 levels [ $<<0.01]$ and increased OAT1 levels $[p<0.01]$. In addition, both luteolin $[3.125 \mu \mathrm{mol} / \mathrm{L}: \mathrm{p}<0.05 ; 6.25 \mu \mathrm{mol} / \mathrm{L}: \mathrm{p}<0.05]$ and luteoloside $[3.125 \mu \mathrm{mol} / \mathrm{L}: \mathrm{p}<0.01 ; 6.25 \mu \mathrm{mol} / \mathrm{L}: \mathrm{p}<$ $0.01]$ but not apigenin treatment increased OAT1 levels in normal HK-2 cells.

\section{Effects of active components on the levels of GLUT9, URAT1 and OAT1 in HK-2 cells induced by uric acid}

The effects of luteolin, luteoloside and apigenin on GLUT9, URAT1 and OAT1 in uric acid-induced HK-2 cells were shown in Fig. 4. There was a significant treatment effect on GLUT9 [ $p<0.01]$, URAT1 [ $p<0.01]$ and OAT1 [ $p<0.01$ ] levels according to one-way ANOVA. Uric acid significantly increased GLUT9 [ $<<0.01]$ and UAT1 $[p<0.01]$ levels but decreased OAT1 [ $<<0.01]$ levels in HK-2 cells. Compared with uric acid-

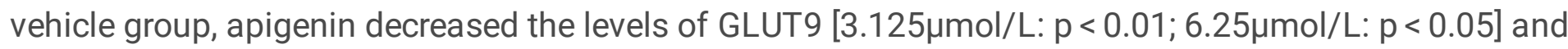

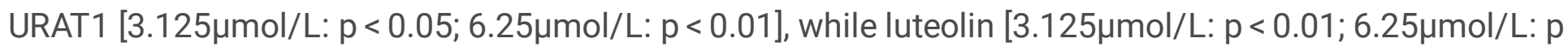
$<0.01]$ and luteoloside $[3.125 \mu \mathrm{mol} / \mathrm{L}: \mathrm{p}<0.01 ; 6.25 \mu \mathrm{mol} / \mathrm{L}: \mathrm{p}<0.01]$ increased OAT1 levels. In addition, benzbromarone not only reduced GLUT9 and UAT1 levels but also elevated OAT1 levels.

\section{Effects of active components on serum uric acid, urea nitrogen, adenosine deaminase and hepatic xanthine oxidase levels in gouty mice}


As shown in Table 1, one-way ANOVA indicated a significant treatment effect on serum uric acid [p $<0.01]$ and urea nitrogen $[p<0.01]$ levels. Post hoc test showed that PO significantly increased serum uric acid $[p<0.01]$, urea nitrogen $[p<0.01]$ and adenosine deaminase $[p<0.05]$ levels in gouty mice as compared with the Control-vehicle group. Compared with PO-vehicle group, allopurinol, luteolin, luteoloside and apigenin significantly reversed the elevation of serum uric acid and urea nitrogen concentrations. In addition, luteolin and apigenin attenuated the increase of serum adenosine deaminase levels.

Table 1

Effects of drugs in different groups on serum uric acid, BUN and ADA levels in hyperuricemia mice (Mean $\pm S D, n=10$ )

\begin{tabular}{|c|c|c|c|c|}
\hline Group & $\begin{array}{l}\text { Dose } \\
\mathrm{mg} / \mathrm{kg}\end{array}$ & $\begin{array}{l}\text { Uric acid } \\
(\mu \mathrm{mol} / \mathrm{L})\end{array}$ & $\begin{array}{l}\text { Urea nitrogen } \\
\text { (mmol/L) }\end{array}$ & $\begin{array}{l}\text { Adenosine deaminase } \\
(\mathrm{U} / \mathrm{L})\end{array}$ \\
\hline Control-vehicle & - & $16.73 \pm 2.76$ & $4.66 \pm 0.82$ & $2.18 \pm 0.56$ \\
\hline PO-vehicle & - & $79.77 \pm 10.70^{\# \#}$ & $7.12 \pm 0.96^{\# \#}$ & $3.48 \pm 0.80^{\#}$ \\
\hline PO-allopurinol & 10 & $14.89 \pm 3.39^{\star \star}$ & $7.00 \pm 0.73$ & $2.87 \pm 1.32$ \\
\hline PO-luteolin & 20 & $30.09 \pm 9.97^{\star *}$ & $5.50 \pm 0.75^{\star \star}$ & $2.21 \pm 0.43^{*}$ \\
\hline PO-luteolin & 50 & $20.36 \pm 6.31^{\star \star}$ & $3.00 \pm 0.84^{\star *}$ & $2.46 \pm 0.95^{*}$ \\
\hline PO-luteoloside & 20 & $29.01 \pm 11.61^{* *}$ & $4.95 \pm 0.76^{\star *}$ & $2.53 \pm 0.94$ \\
\hline PO-luteoloside & 50 & $21.25 \pm 4.42^{* \star}$ & $5.01 \pm 0.51^{* \star}$ & $2.85 \pm 0.65$ \\
\hline PO-apigenin & 20 & $15.52 \pm 2.11^{\star *}$ & $2.43 \pm 0.26^{\star \star}$ & $2.49 \pm 0.53^{*}$ \\
\hline PO-apigenin & 50 & $17.24 \pm 2.85^{\star *}$ & $2.50 \pm 0.29^{* *}$ & $2.45 \pm 0.73^{*}$ \\
\hline
\end{tabular}

As shown in Table 2, one-way ANOVA showed a significant treatment effect on hepatic xanthine oxidase levels [ $<0.01]$. PO [ $<0.05]$ significantly increased xanthine oxidase levels in liver, while luteolin, luteoloside and apigenin administration reversed the elevation. 
Table 2

Effects of drugs in different groups on liver xanthine oxidase activity in hyperuricemia mice (Mean $\pm S D, n=10)$

\begin{tabular}{|lll|}
\hline Group & $\begin{array}{l}\text { Dose } \\
\mathrm{mg} / \mathrm{kg}\end{array}$ & $\begin{array}{l}\text { Xanthine oxidase } \\
\text { (U/gprot) }\end{array}$ \\
\hline Control-vehicle & - & $52.78 \pm 1.25$ \\
\hline PO-vehicle & - & $58.03 \pm 3.26^{\#}$ \\
\hline PO-allopurinol & 10 & $49.99 \pm 1.39^{\star *}$ \\
\hline PO-luteolin & 20 & $50.06 \pm 2.64^{* \star}$ \\
\hline PO-luteolin & 50 & $51.30 \pm 0.50^{* \star}$ \\
\hline PO-luteoloside & 20 & $52.15 \pm 1.51^{* \star}$ \\
\hline PO-luteoloside & 50 & $52.56 \pm 1.90^{* \star}$ \\
\hline PO-apigenin & 20 & $54.82 \pm 1.72^{*}$ \\
\hline PO-apigenin & 50 & $54.71 \pm 1.65^{*}$ \\
\hline$\#_{p} \mathrm{p}<0.05$ versus Control-vehicle group; ${ }^{*} \mathrm{p}<0.05,{ }^{* *} \mathrm{p}<0.01$ versus PO-vehicle group \\
\hline
\end{tabular}

\section{Effects of active components on renal transporter levels in gouty mice}

According to one-way ANOVA, there was a significant treatment factor on GLUT9 [ $p<0.01$ ], URAT1 [ $p<$ 0.01 ] and OAT1 [ $p<0.01$ ] levels in kidney (Fig. 5). Post hoc test showed that PO significantly increased the levels of GLUT9 [p < 0.01], URAT1 [p < 0.01] but decreased the levels of OAT1 [p < 0.01]. Both luteolin [20 mg/kg: $p<0.01 ; 50 \mathrm{mg} / \mathrm{kg}: \mathrm{p}<0.01$ ] and luteoloside [20 mg/kg: $p<0.01 ; 50 \mathrm{mg} / \mathrm{kg}: p<0.01$ ] pretreatment prevented the reduction of OAT1 levels but not affected GLU9 and URAT1 levels. Only apigenin prevented the elevation of GLUT9 [20 mg/kg: $p<0.01 ; 50 \mathrm{mg} / \mathrm{kg}: \mathrm{p}<0.01]$ and URAT1 [20 $\mathrm{mg} / \mathrm{kg}: \mathrm{p}<0.01 ; 50 \mathrm{mg} / \mathrm{kg}: \mathrm{p}<0.01]$ in the kidney.

\section{Interaction between active components and TLR4/NLRP3 by molecular docking}

Molecular docking simulation by AutoDock Vina demonstrated the active components were in the pocket of TLR4-MD2 complex and NLRP3 protein (Fig. 6,7). The simulation showed that luteolin, luteoloside and apigenin interact with TLR4/MD-2 and NLRP3 by hydrophobic and hydrogen bonding interactions. The binding energies between luteolin/luteoloside/apigenin and the proteins were shown in Table 3, indicating the putative inhibitory activity of the active components on inflammation. 
Table 3

The affinity $(\mathrm{kcal} / \mathrm{mol})$ of luteolin, luteoloside and apigenin binding with TLR4 and NLRP3.

\begin{tabular}{|lll|}
\hline Group & TLR4 & NLRP3 \\
\hline Luteolin & -8.2 & -8.4 \\
\hline Luteoloside & -8.8 & -9.2 \\
\hline Apigenin & -7.9 & -8.6 \\
\hline
\end{tabular}

\section{Effects of active components on renal TLR4-MyD88-NLRP3- IL-1 $\beta$ in gouty mice}

As shown in Fig. 8, one-way ANOVA showed a significant treatment factor on TLR4 [p < 0.01], MyD88 [p < $0.01]$, NLRP3 [ $<0.01]$ and IL-1 $\beta[p<0.01$ ] levels. Post hoc test showed that PO significantly increased the levels of TLR4 [p $<0.01]$, MyD88 [p $<0.01]$, NLRP3[p $<0.01]$ and IL-1 $\beta[p<0.01]$. Luteolin pretreatment inhibited the increase of TLR4 [20 mg/kg: $p<0.01 ; 50 \mathrm{mg} / \mathrm{kg}: \mathrm{p}<0.01]$, MyD88[20 mg/kg: $p<0.01 ; 50$ $\mathrm{mg} / \mathrm{kg}: \mathrm{p}<0.01]$, NLRP3 [20 mg/kg: $p<0.01 ; 50 \mathrm{mg} / \mathrm{kg}: \mathrm{p} \otimes 0.05]$ and IL-1 $\beta[20 \mathrm{mg} / \mathrm{kg}: \mathrm{p}<0.01 ; 50 \mathrm{mg} / \mathrm{kg}$ : $p<0.01]$ in the kidney. Luteoloside inhibited the increase of NLRP3 [20 mg/kg: $p<0.01 ; 50 \mathrm{mg} / \mathrm{kg}: \mathrm{p}<$ $0.01]$ and IL-1 $\beta$ [20 mg/kg: $p<0.01 ; 50 \mathrm{mg} / \mathrm{kg}: \mathrm{p}<0.01]$ in the kidney. In addition, apigenin inhibited the increase of TLR4 [20 mg/kg: $p<0.01 ; 50 \mathrm{mg} / \mathrm{kg}: \mathrm{p}<0.01$ ], MyD88[20 mg/kg: $p<0.05 ; 50 \mathrm{mg} / \mathrm{kg}: \mathrm{p}<0.01$ ], NLRP3 [20 mg/kg: $p<0.01 ; 50 \mathrm{mg} / \mathrm{kg}: p<0.01]$ and IL-1 $[20 \mathrm{mg} / \mathrm{kg}: p<0.01 ; 50 \mathrm{mg} / \mathrm{kg}: p<0.01]$ in the kidney.

One-way ANOVA showed a significant treatment effect on IL-1 $\beta[p<0.05]$ or TNF-a $[p<0.05]$ levels among the groups (Table 4). The post hoc test indicated that PO induced an increase of IL-1 $\beta$ and TNF- $\alpha$ in the serum. In contrast, all of the three active components decreased the levels of IL-1 $\beta$ and TNF-a in hyperuricemia mice. 
Table 4

Effects of drugs in each group on IL-1 $\beta$ and TNF- $\alpha$ in PO-induced hyperuricemia mice (Mean \pm $\mathrm{SD}, \mathrm{n}=10$ )

\begin{tabular}{|c|c|c|c|}
\hline Group & $\begin{array}{l}\text { Dose } \\
\mathrm{mg} / \mathrm{kg}\end{array}$ & $\begin{array}{l}\text { IL-1 } \beta \\
(\mathrm{pg} / \mathrm{ml})\end{array}$ & $\begin{array}{l}\text { TNF-a } \\
(\mathrm{pg} / \mathrm{ml})\end{array}$ \\
\hline Control-vehicle & - & $54.38 \pm 2.66$ & $51.21 \pm 3.46$ \\
\hline PO-vehicle & - & $58.03 \pm 3.26^{\#}$ & $80.77 \pm 8.50^{\# \#}$ \\
\hline PO-allopurinol & 10 & $50.71 \pm 1.84^{\star \star}$ & $48.89 \pm 8.30^{\star \star}$ \\
\hline PO-luteolin & 20 & $49.50 \pm 2.82^{\star \star}$ & $51.22 \pm 7.72^{\star \star}$ \\
\hline PO-luteolin & 50 & $51.30 \pm 0.50^{\star *}$ & $51.94 \pm 10.98^{\star \star}$ \\
\hline PO-luteoloside & 20 & $50.13 \pm 3.25^{\star \star}$ & $63.06 \pm 10.71^{*}$ \\
\hline PO-luteoloside & 50 & $53.46 \pm 2.03^{*}$ & $61.69 \pm 14.70^{\star}$ \\
\hline PO-apigenin & 20 & $52.82 \pm 4.03^{\star *}$ & $77.01 \pm 14.19^{*}$ \\
\hline PO-apigenin & 50 & $54.71 \pm 1.65^{\star}$ & $68.33 \pm 10.73^{\star}$ \\
\hline \multicolumn{4}{|c|}{${ }^{\#} \mathrm{p}<0.05,{ }^{\# \#} \mathrm{p}<0.01$ versus Control-vehicle group; ${ }^{*} \mathrm{p}<0.05,{ }^{* *} \mathrm{p}<0.01$ versus PO-vehicle group } \\
\hline
\end{tabular}

As shown in Fig. 9, the structures of glomerular and renal tubular epithelial cells in the Control-vehicle animals were clear. Consistently, there is no apparent inflammatory reaction in the kidney of normal animals. In gouty mice induced by PO, there was necrosis of the renal tubular epithelial cells. Proliferation and inflammation were observed in the surrounding interstitium. Dilation and calcification occurred in renal tubules. Pretreatment with allopurinol prevented the inflammatory response, attenuated the dilation of renal tubules, and improved renal tubular epithelial cells' structure. Luteolin at $20 \mathrm{mg} / \mathrm{kg}$ slightly decreased renal tubular necrosis and interstitial proliferation, while there was only slightly dilation of renal tubules and inflammatory cell accumulation after administration with luteolin at $50 \mathrm{mg} / \mathrm{kg}$. Inflammatory cell accumulation, renal tubular necrosis and interstitial proliferation were still observed by pretreatment with luteoloside at $20 \mathrm{mg} / \mathrm{kg}$ but ameliorated by pretreatment with luteoloside at $50 \mathrm{mg} / \mathrm{kg}$. Apigenin at $20 \mathrm{mg} / \mathrm{kg}$ could not improve the accumulation of inflammatory cells, necrosis of renal tubules, and interstitial hyperplasia, while apigenin at $50 \mathrm{mg} / \mathrm{kg}$ reduced the accumulation of inflammatory cells and weakened the dilation of the renal tubule.

\section{Discussion}


In the previous study, we found that extracts from Lagotis brachystachya produced anti-hyperuricemic effects in mice and confirmed that active fractions of Lagotis brachystachya (Xiong et al., 2018). Then we separated three potential components (luteolin, luteoloside and apigenin) from the active fraction (Zhu et al., 2019). In this context, the three components' effects were evaluated in vitro and in vivo in the present study for the first time. Increasing evidence shows that elevated blood uric acid is an independent risk factor for kidney disease and plays an important role in the occurrence and development of kidney disease (Kanbay et al., 2017; Tsai et al., 2017). The dysfunctions of uric acid homeostasis characterize hyperuricemia. The results firstly indicated the potential efficacy of luteolin, luteoloside and apigenin against hyperuricemia. Xanthine oxidase is the rate-limiting enzyme in the metabolic pathway of purine nucleosides. It is the final link in regulating uric acid production and plays a dominant role in the pathogenesis of hyperuricemia (Serrano et al., 2020). In the present study, all the three components significantly decreased hepatic xanthine oxidase activity in PO-induced hyperuricemic mice, which indicated the inhibitory activity of uric acid generation by luteolin, luteoloside and apigenin. These results were partly consistent with a previous study showing that luteolin interacted with the primary amino acid residues located within the active site pocket of xanthine oxidase by molecular docking and biochemical analysis (Lin et al., 2014; Yan et al., 2013).

On the other hand, urate transporters regulate the excretion of uric acid in the body. The imbalance of the renal uric acid transport system is one of the main causes of hyperuricemia (Pavelcova et al., 2020). As a membrane protein, OAT1 regulates renal uric acid excretion initially (Otani et al., 2017). URAT1, which is expressed in the proximal tubule epithelial cells' brush border, is responsible for the reabsorption of urate. Organic anions which accumulate in renal tubular epithelial cells have a high affinity with URAT1 (Anzai and Endou, 2011). The intracellular anions exchange with urate in the tubule lumen, leading to increased uric acid reabsorption. In addition to URAT1, GLUT9, which influences the renal handling of uric acid and modulates serum urate levels, is in response to the treatment in patients with uric acid overproduction (Torres and Puig, 2018). Therefore, changes in the levels of OAT1, URAT1 and GLUT9 reflect the degree of hyperuricemia development. To elucidate the effects of the three components on transporters, OAT1, URAT1, and GLUT9 levels in response to luteolin, luteoloside and apigenin treatment were measured both in vitro and in vivo. In the vitro experiment, only luteolin and luteoloside affected OAT1 levels but not URAT1 and GLUT9 in normal HK-2 cells. When the cells were pre-treated by uric acid, luteolin and luteoloside still increased OAT1 levels in uric acid-treated HK-2 cells. While apigenin decreased the URAT1 and GLUT9 levels. In vivo study, PO caused the reduction of OAT1 but the elevation of URAT1 and GLUT9 in the kidney of mice. However, the three components differently exerted their action on the transporters. In detail, luteolin and luteoloside significantly increased the OAT1 levels, while apigenin decreased URAT1 and GLUT9 levels in PO-induced mice. These results explained the excellent therapeutic efficacy of Lagotis brachystachya, as the herb had different components exerting dual anti-hyperuricemic actions. The active components could inhibit the production of uric acid by inhibiting hepatic xanthine oxidase and promoting renal urate excretion by regulating renal urate transporters in hyperuricemia. Thus, the presence of luteolin, luteoloside and apigenin in Lagotis brachystachya could be responsible for the activity against PO-induced hyperuricemia. 
Accumulating evidence demonstrates the correlation between inflammation and hyperuricemia(AmezcuaCastillo et al., 2020; Rahmi et al., 2020; Su et al., 2020). Studies have shown that excessive urate can activate TLR4 and NLRP3 signals in hyperuricemia (So, 2007a). After binds to the CD14 receptor, urate is recognized by TLR4 to form a TLR4/MD2/CD14 complex (So, 2007b). The activated TLR4 transduces the signal into the cell through the intracytoplasmic domain and subsequently activates NF-kB, which initiates gene expression related to inflammation. The potential anti-inflammatory activity of the three compounds was firstly evaluated by molecular docking. The docking results showed that all of the three components could enter the pocket of TLR4 and NLRP3 and thus obtain a high affinity with these proteins. These observations suggested that luteolin, luteoloside and apigenin could block the activation of an inflammatory response, which could be involved in the treatment for hyperuricemia. Subsequently, the inflammation-related mechanism was evaluated in vivo experiments. In line with the previous study (Guo et al., 2020), PO caused the elevation of TLR4 and NLRP3 levels in the kidney. On the contrary, treatments with luteolin, luteoloside or apigenin inhibited renal TLR4/MyD88/NLRP3/IL-1 $\beta$ levels, as well as serum pro-inflammatory cytokine levels in PO-induced hyperuricemic mice, indicating that the inflammation induced by hyperuricemia was effectively normalized. This finding was in line with the histopathological examination showing these three active components reversed the accumulation of inflammatory cells. Similarly, a recent study also showed that luteolin downregulated the TLR4/MyD88 pathway in monosodium urate-induced gouty arthritis rats (Shen et al., 2020). In addition, several studies reported the inhibitory activity of luteoloside and apigenin on NLRP3 inflammasome in vitro (Fan et al., 2014; Yamagata et al., 2019). These observations suggested that the anti-inflammatory activity of luteolin, luteoloside and apigenin may be mediated by targeting TLR4/NLRP3.

\section{Conclusion}

This study demonstrated that luteolin, luteoloside and apigenin, the three active components extracted from Lagotis brachystachya possessed transporters' regulatory activity against high levels of uric acid in vitro. In vivo study on PO-induced hyperuricemic mice showed that luteolin, luteoloside and apigenin exerted dual regulatory roles in xanthine oxidase activity and transporters. Moreover, the active components showed the anti-inflammatory activity by targeting TLR4/MyD88/NLRP3/IL-1 $\beta$ signaling pathway in the kidney. Therefore, the present supports that luteolin, luteoloside and apigenin are the potential candidates for hyperuricemia treatment.

\section{Declarations}

\section{Author contributions}

J.Z., H.C. and L.Y. conceived of the project. J.Z., H.Y., W.H. and J.C. performed the experiments. J.Z. and Y.L. analyzed data. L.Y. did molecular docking. J.Z., H.C. and L.Y. wrote the manuscript. All authors read and approved the submission. 


\section{Role of Funding Source}

The project was supported by grants from the National Natural Science Foundation of China (No. 82060757), the Science and Technology Research Project of Jiangxi Provincial Department of Education (No. GJJ190632) and the Science and Technology Project of Jiangxi Provincial Administration of Traditional Chinese Medicine (No. 2019A004, 2019A258).

\section{Compliance with Ethical Standards}

\section{Conflict of interest}

The authors declare that they have no conflicts of interest.

\section{Ethics Approval}

All animal procedure was in accordance with guidelines from China Council on Animal Care and was approved by the Animal Commission of Jiangxi University of Traditional Chinese Medicine.

\section{References}

1. Amezcua-Castillo, L. M., Juarez-Vicuna, Y., Marquez-Velasco, R. and Amezcua-Guerra, L. M. (2020). Activation Status of NLRP3 Inflammasome in Peripheral Blood Mononuclear Cells From Patients With Gout Flare. J Clin Rheumatol 26, S208-S212.

2. Anzai, N. and Endou, H. (2011). Urate transporters: an evolving field. Semin Nephro/31, 400-409.

3. Azevedo, V. F., Kos, I. A., Vargas-Santos, A. B., da Rocha Castelar Pinheiro, G. and Dos Santos Paiva, E. (2019). Benzbromarone in the treatment of gout. Adv Rheumato/ 59, 37.

4. De Nardo, D. and Latz, E. (2011). NLRP3 inflammasomes link inflammation and metabolic disease. Trends Immuno/ 32, 373-379.

5. Dong, Y., Zhao, T., Ai, W., Zalloum, W. A., Kang, D., Wu, T., Liu, X. and Zhan, P. (2019). Novel urate transporter 1 (URAT1) inhibitors: a review of recent patent literature (2016-2019). Expert Opin Ther Pat 29, 871-879.

6. Fan, S. H., Wang, Y. Y., Lu, J., Zheng, Y. L., Wu, D. M., Li, M. Q., Hu, B., Zhang, Z. F., Cheng, W. and Shan, Q. (2014). Luteoloside suppresses proliferation and metastasis of hepatocellular carcinoma cells by inhibition of NLRP3 inflammasome. Plos One 9, e89961.

7. Guo, L. F., Chen, X., Lei, S. S., Li, B., Zhang, N. Y., Ge, H. Z., Yang, K., Lv, G. Y. and Chen, S. H. (2020). Effects and Mechanisms of Dendrobium officinalis Six Nostrum for Treatment of Hyperuricemia with Hyperlipidemia. Evidence-based complementary and alternative medicine : eCAM 2020, 2914019. 
8. Kanbay, M., Solak, Y., Afsar, B., Nistor, I., Aslan, G., Caglayan, O. H., Aykanat, A., Donciu, M. D., Lanaspa, M. A., Ejaz, A. A., Johnson, R. J. and Covic, A. (2017). Serum Uric Acid and Risk for Acute Kidney Injury Following Contrast. Angiology 68, 132-144.

9. Lim, H., Min, D. S., Park, H. and Kim, H. P. (2018). Flavonoids interfere with NLRP3 inflammasome activation. Toxicol Appl Pharmaco/ 355, 93-102.

10. Lin, W. Q., Xie, J. X., Wu, X. M., Yang, L. and Wang, H. D. (2014). Inhibition of xanthine oxidase activity by gnaphalium affine extract. Chin Med Sci J 29, 225-230.

11. Ma, C., Yang, X., Lv, Q., Yan, Z., Chen, Z., Xu, D., Liu, X., Yang, W. and Xing, S. (2020). Soluble uric acid induces inflammation via TLR4/NLRP3 pathway in intestinal epithelial cells. Iran J Basic Med Sci 23, 744-750.

12. Otani, N., Ouchi, M., Hayashi, K., Jutabha, P. and Anzai, N. (2017). Roles of organic anion transporters (OATs) in renal proximal tubules and their localization. Anat Sci Int 92, 200-206.

13. Pavelcova, K., Bohata, J., Pavlikova, M., Bubenikova, E., Pavelka, K. and Stiburkova, B. (2020). Evaluation of the Influence of Genetic Variants of SLC2A9 (GLUT9) and SLC22A12 (URAT1) on the Development of Hyperuricemia and Gout. J Clin Med 9, 2510.

14. Rahmi, E. P., Kumolosasi, E., Jalil, J., Husain, K., Buang, F., Abd Razak, A. F. and Jamal, J. A. (2020). Anti-hyperuricemic and Anti-inflammatory Effects of Marantodes pumilum as Potential Treatment for Gout. Front Pharmacol 11, 289.

15. Romero, C. A., Remor, A., Latini, A., De Paul, A. L., Torres, A. I. and Mukdsi, J. H. (2017). Uric acid activates NRLP3 inflammasome in an in-vivo model of epithelial to mesenchymal transition in the kidney. J Mol Histol 48, 209-218.

16. Serrano, J. L., Figueiredo, J., Almeida, P. and Silvestre, S. (2020). From Xanthine Oxidase Inhibition to In Vivo Hypouricemic Effect: An Integrated Overview of In Vitro and In Vivo Studies with Focus on Natural Molecules and Analogues. Evidence-based complementary and alternative medicine : eCAM 2020, 9531725.

17. Shekelle, P. G., Newberry, S. J., FitzGerald, J. D., Motala, A., O'Hanlon, C. E., Tariq, A., Okunogbe, A., Han, D. and Shanman, R. (2017). Management of Gout: A Systematic Review in Support of an American College of Physicians Clinical Practice Guideline. Ann Intern Med 166, 37-51.

18. Shen, R., Ma, L. and Zheng, Y. (2020). Anti-inflammatory effects of luteolin on acute gouty arthritis rats via TLR/MyD88/NF-kappaB pathway. Zhong Nan Da Xue Xue Bao Yi Xue Ban 45, 115-122.

19. So, A. (2007a). [New knowledge on the pathophysiology and therapy of gout]. Z Rheumato/ 66, 562, 564-567.

20. So, A. (2007b). [Recent advances in the pathophysiology of hyperuricemia and gout]. Rev Med Suisse 3, 720, 722-724.

21. Su, H. Y., Yang, C., Liang, D. and Liu, H. F. (2020). Research Advances in the Mechanisms of Hyperuricemia-Induced Renal Injury. Biomed Res Int 2020, 5817348.

22. Torres, R. J. and Puig, J. G. (2018). GLUT9 influences uric acid concentration in patients with LeschNyhan disease. Int J Rheum Dis 21, 1270-1276. 
23. Tsai, C. W., Lin, S. Y., Kuo, C. C. and Huang, C. C. (2017). Serum Uric Acid and Progression of Kidney Disease: A Longitudinal Analysis and Mini-Review. Plos One 12, e0170393.

24. Wang, K., Hu, L. and Chen, J. K. (2018). RIP3-deficience attenuates potassium oxonate-induced hyperuricemia and kidney injury. Biomed Pharmacother 101, 617-626.

25. Xiong, W., Zhang, H., Wen, L., Wang, X., Zhong, G., Shi, Y., DU, X. and Zhu, J. (2018). Effect of Lagotis brachystachys Maxim extract on xanthine oxidase and renal urate transporters in hyperuricemia mice. Chinese Journal of New Drugs 27, 1538-1543.

26. Xu, L., Shi, Y., Zhuang, S. and Liu, N. (2017). Recent advances on uric acid transporters. Oncotarget 8 , 100852-100862.

27. Yamagata, K., Hashiguchi, K., Yamamoto, H. and Tagami, M. (2019). Dietary Apigenin Reduces Induction of LOX-1 and NLRP3 Expression, Leukocyte Adhesion, and Acetylated Low-Density Lipoprotein Uptake in Human Endothelial Cells Exposed to Trimethylamine-N-Oxide. J Cardiovasc Pharmacol 74, 558-565.

28. Yan, J., Zhang, G., Hu, Y. and Ma, Y. (2013). Effect of luteolin on xanthine oxidase: inhibition kinetics and interaction mechanism merging with docking simulation. Food Chem 141, 3766-3773.

29. Zhang, X., Yang, X., Wang, M., Li, X., Xia, Q., Xu, S., Xu, J., Cai, G., Wang, L., Xin, L., Zou, Y. and Pan, F. (2016). Association between SLC2A9 (GLUT9) gene polymorphisms and gout susceptibility: an updated meta-analysis. Rheumatol Int 36, 1157-1165.

30. Zhu, J., Shi, Y., Cheng, H., Wang, H., Wang, R. and Li, M. (2019). Chemical Constituents from Lagotis brachystachy. Journal of Chinese Medicinal Materials 42, 552-555.

\section{Figures}

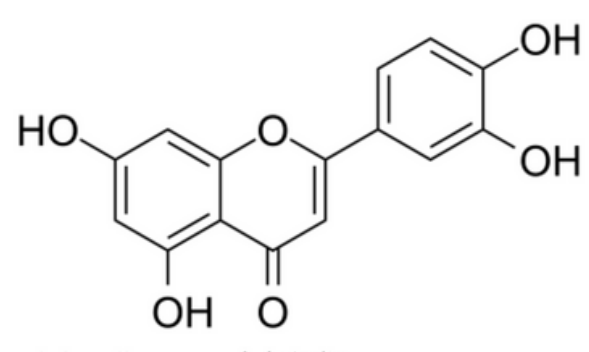

A. Luteolın

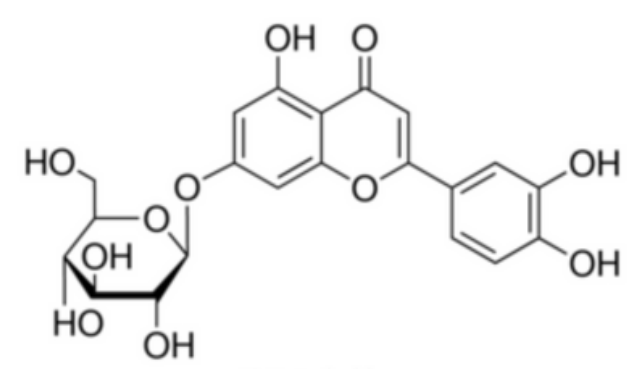

B. Luteoloside

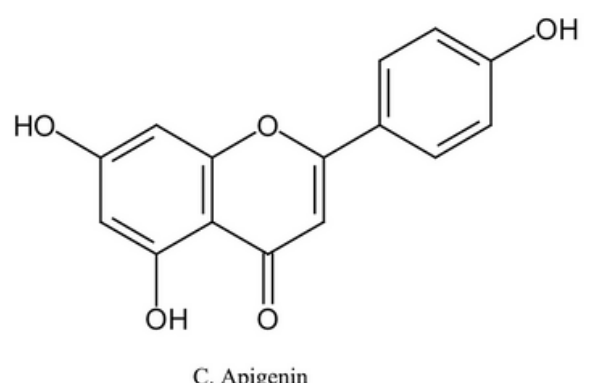

C. Apigenin

\section{Figure 1}

The structure of luteolin, luteoloside and apigenin. 


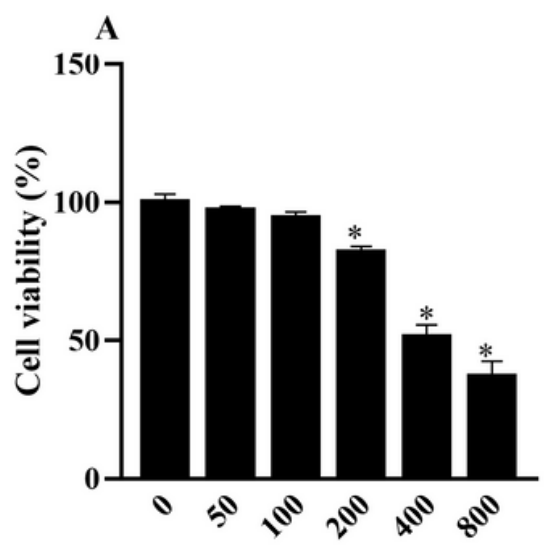

Uric acid $(\mu \mathrm{mol} / \mathrm{L})$

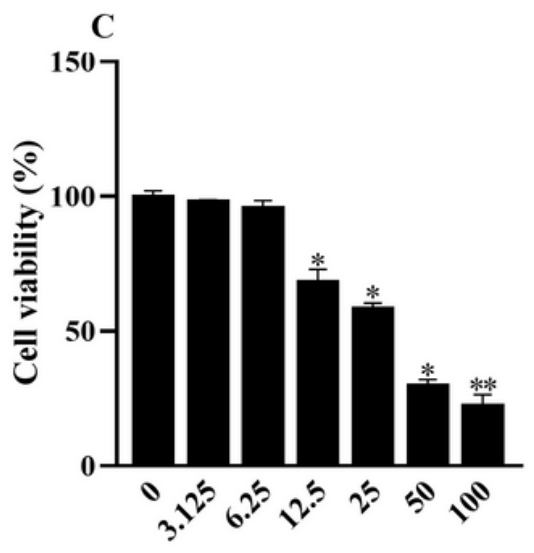

Luteolin $(\mu \mathrm{mol} / \mathrm{L})$

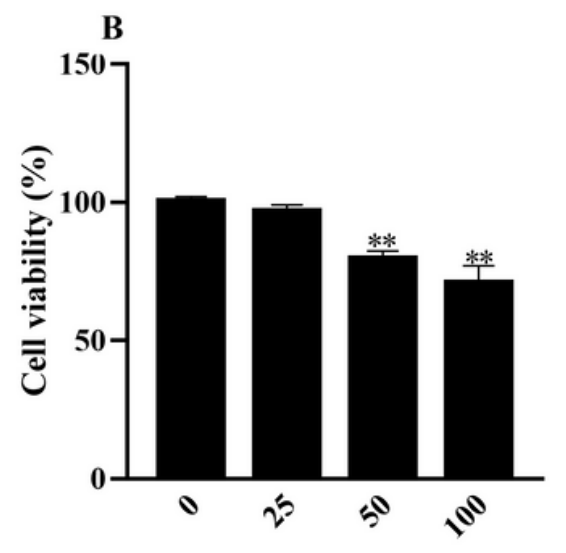

Benzbromarone $(\mu \mathrm{mol} / \mathrm{L})$

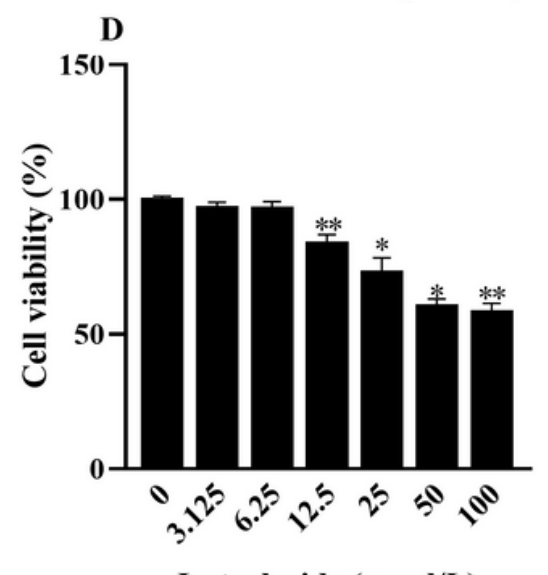

Luteoloside $(\mu \mathrm{mol} / \mathrm{L})$

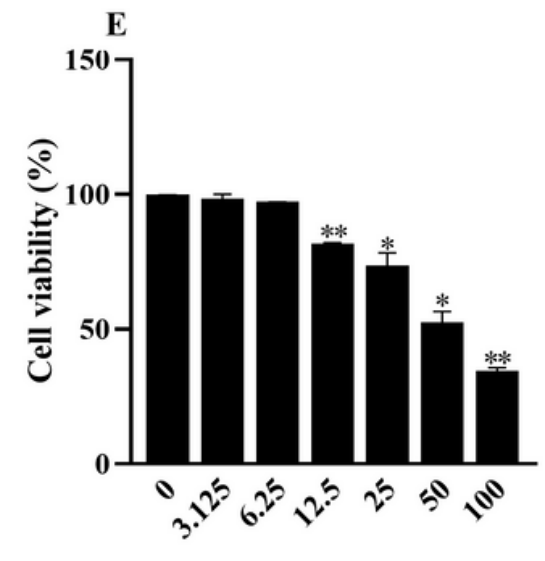

Apigenin $(\mu \mathrm{mol} / \mathrm{L})$

Figure 2

The effects of uric acid, benzbromarone, luteolin, luteoloside and apigenin on cell viability of HK-2 cells. $\star * p<0.01$ versus the vehicle group. 

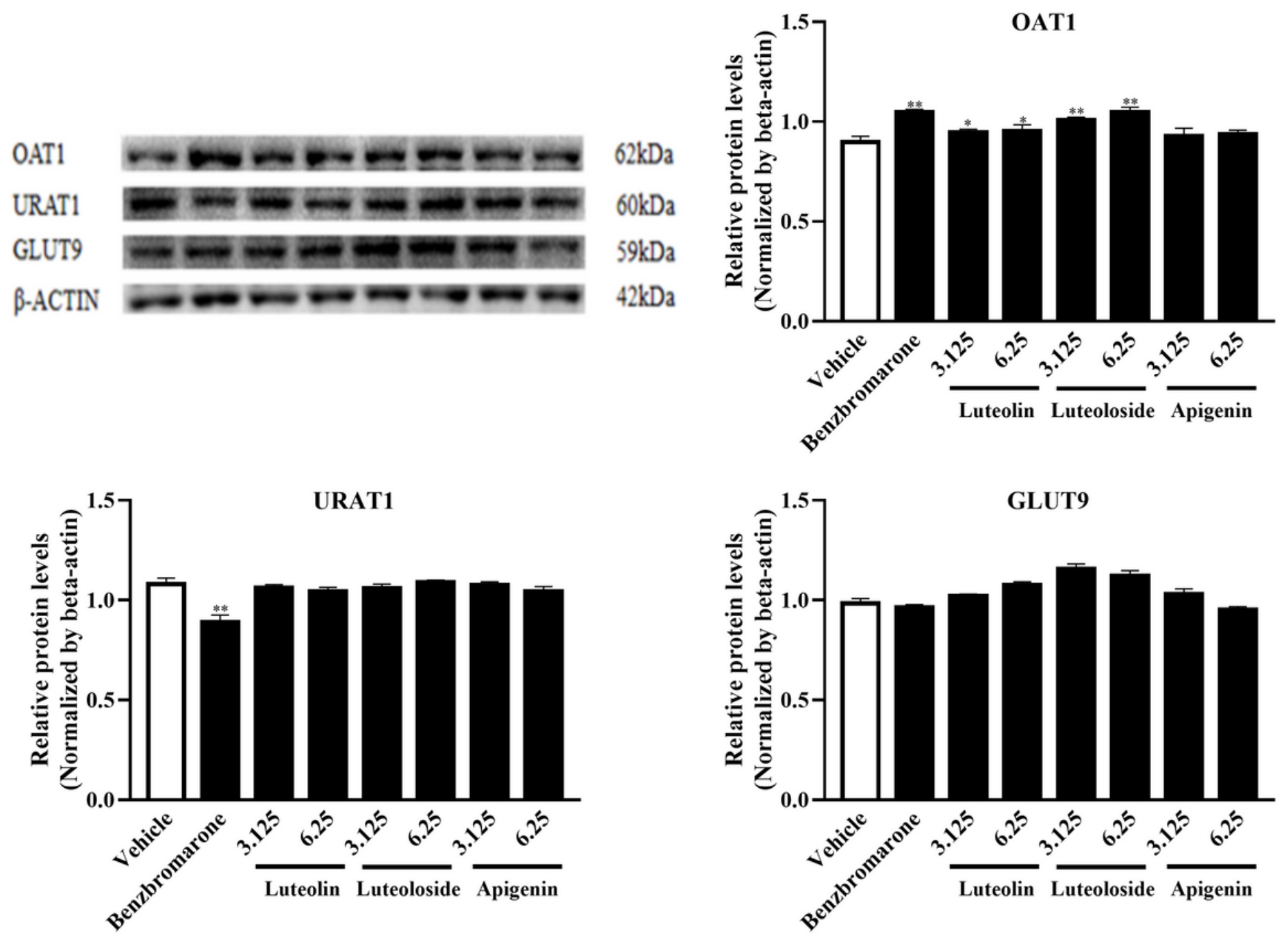

Figure 3

The effects of luteolin, luteoloside and apigenin on OAT1 (A), URAT1 (B) and GLUT9 (D) in normal HK-2 cells. ${ }^{*} p<0.05$ and ${ }^{* \star} p<0.01$ versus the vehicle group. 
A
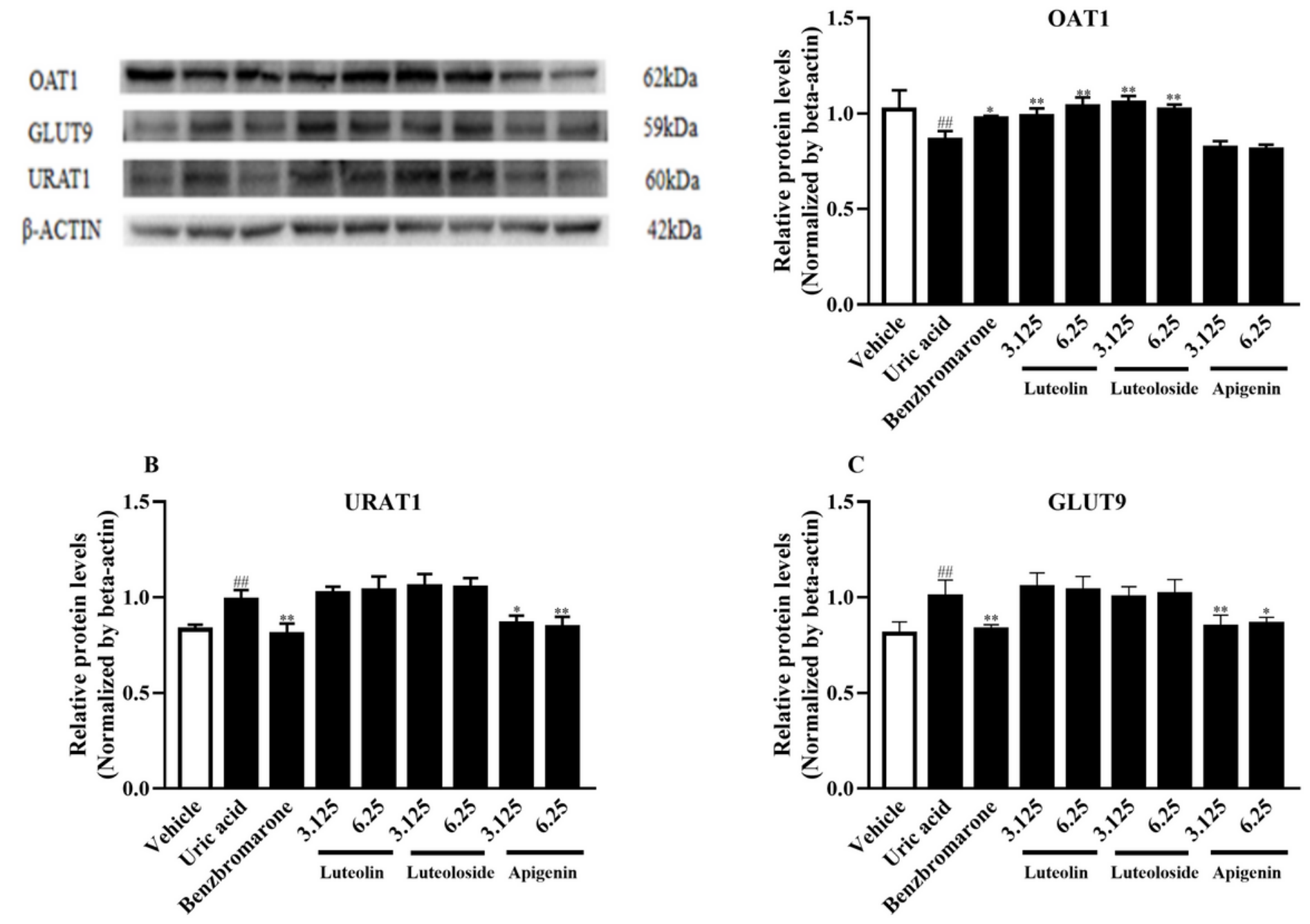

Figure 4

The effects of luteolin, luteoloside and apigenin on OAT1 (A), URAT1 (B) and GLUT9 (D) in uric acidinduced HK-2 cells. \#\#p $<0.01$ versus the Control-vehicle group. ${ }^{*} p<0.05$ and ${ }^{* *} p<0.01$ versus the uric acid-vehicle group. 

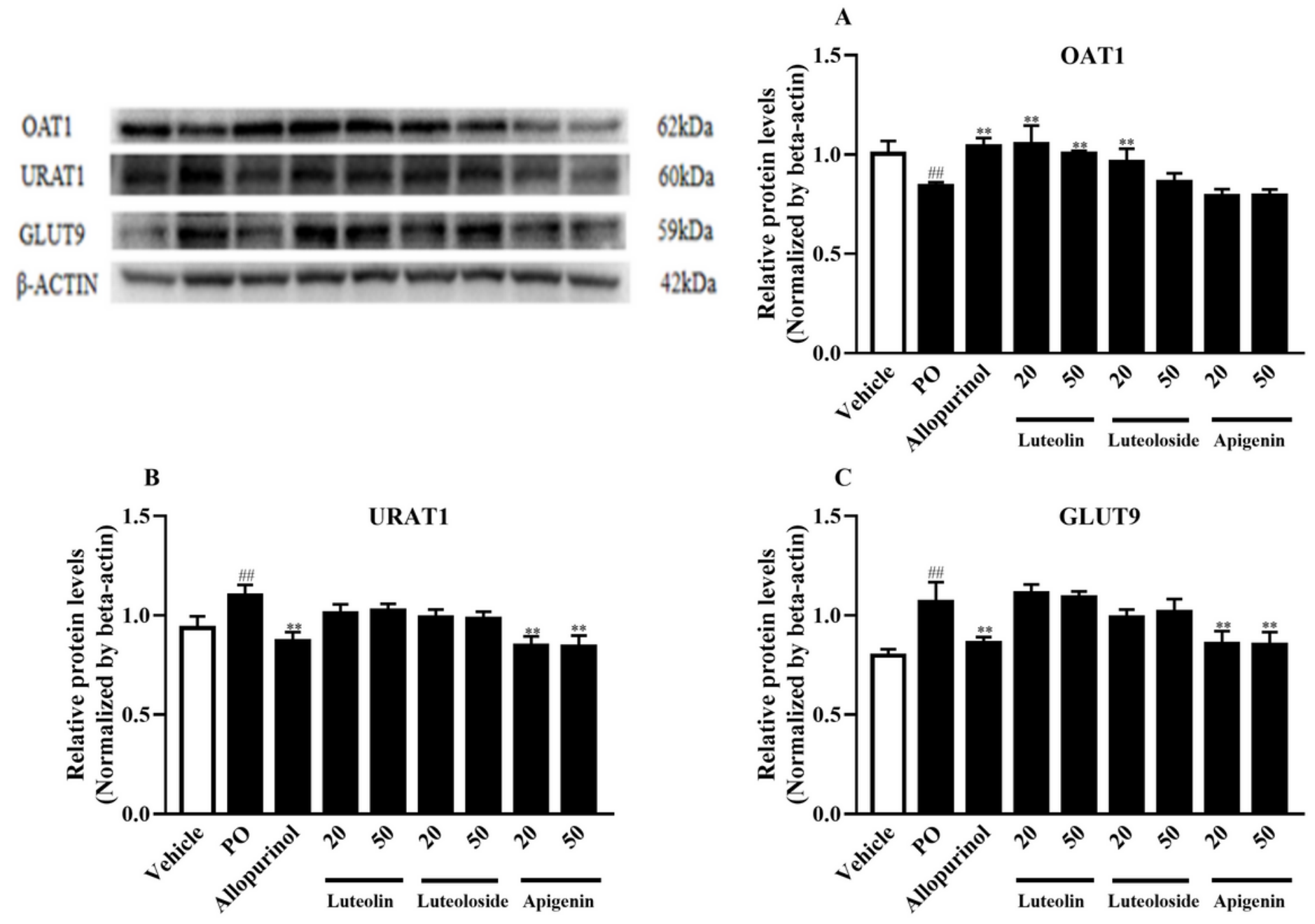

Figure 5

The effects of luteolin, luteoloside and apigenin on OAT1 (A), URAT1 (B) and GLUT9 (D) in PO-induced hyperuricemic mice. $\# \# p<0.01$ versus the Control-vehicle group. ${ }^{*} \mathrm{p}<0.01$ versus the $\mathrm{PO}$-vehicle group. 

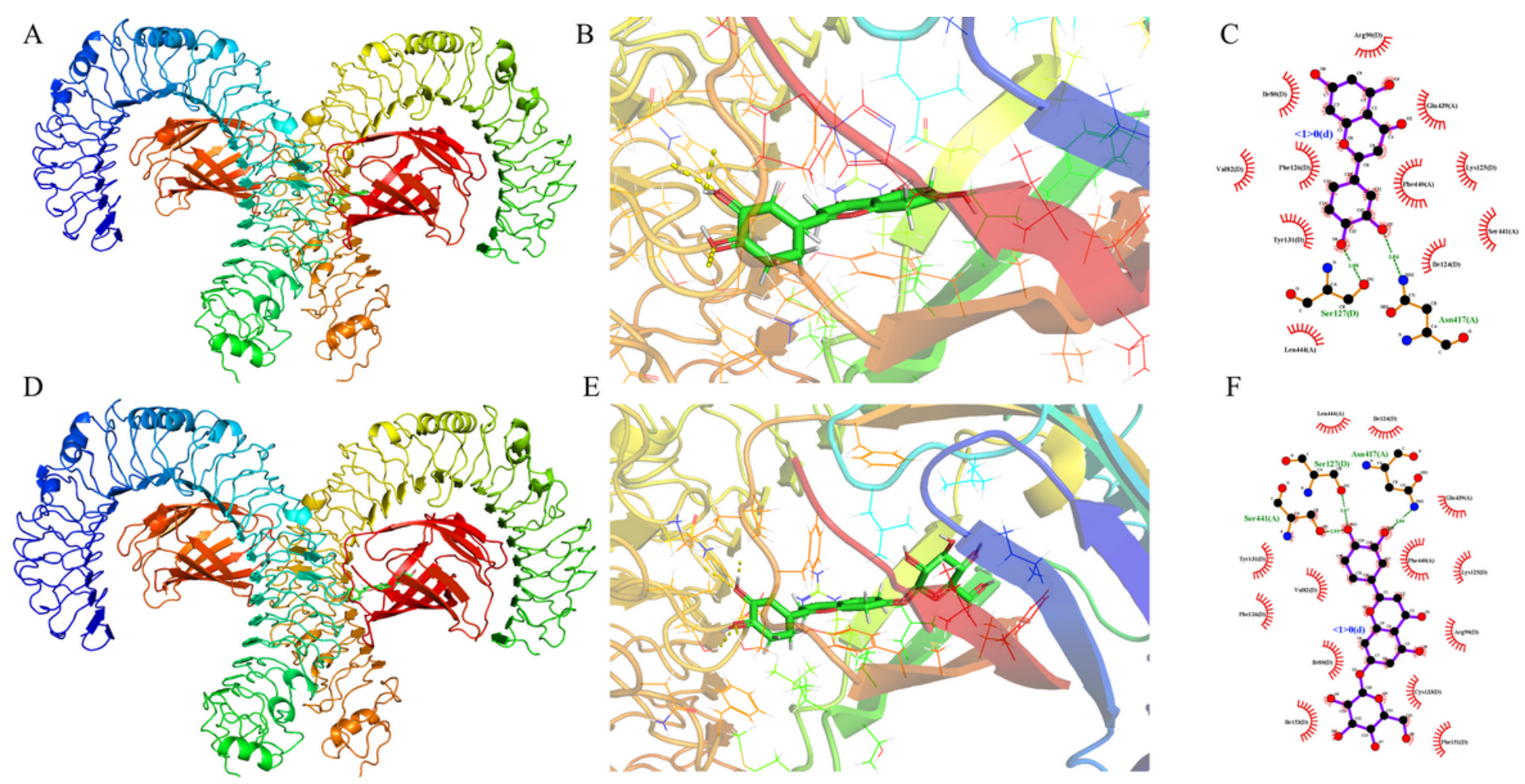

F
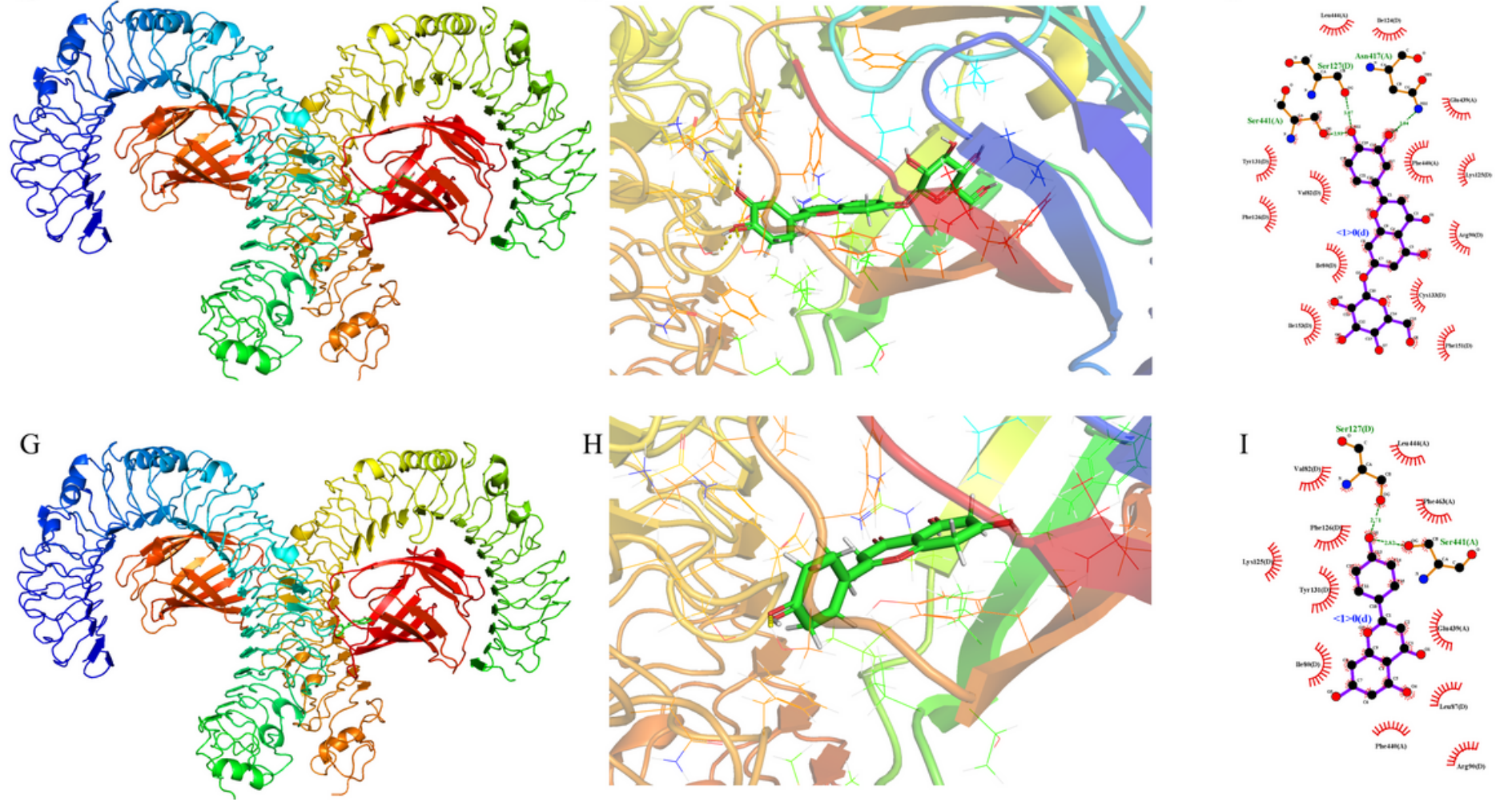

Figure 6

Molecular docking analysis of luteolin, luteoloside and apigenin interacted with TLR4/MD-2. A,D and G show that luteolin, luteoloside and apigenin insert into TLR4/MD-2 complex. B,E and $\mathrm{H}$ enlarge the interacted structures of TLR4 and ligands. C,F,I show the detailed interacted sites between TLR4 and ligands. 

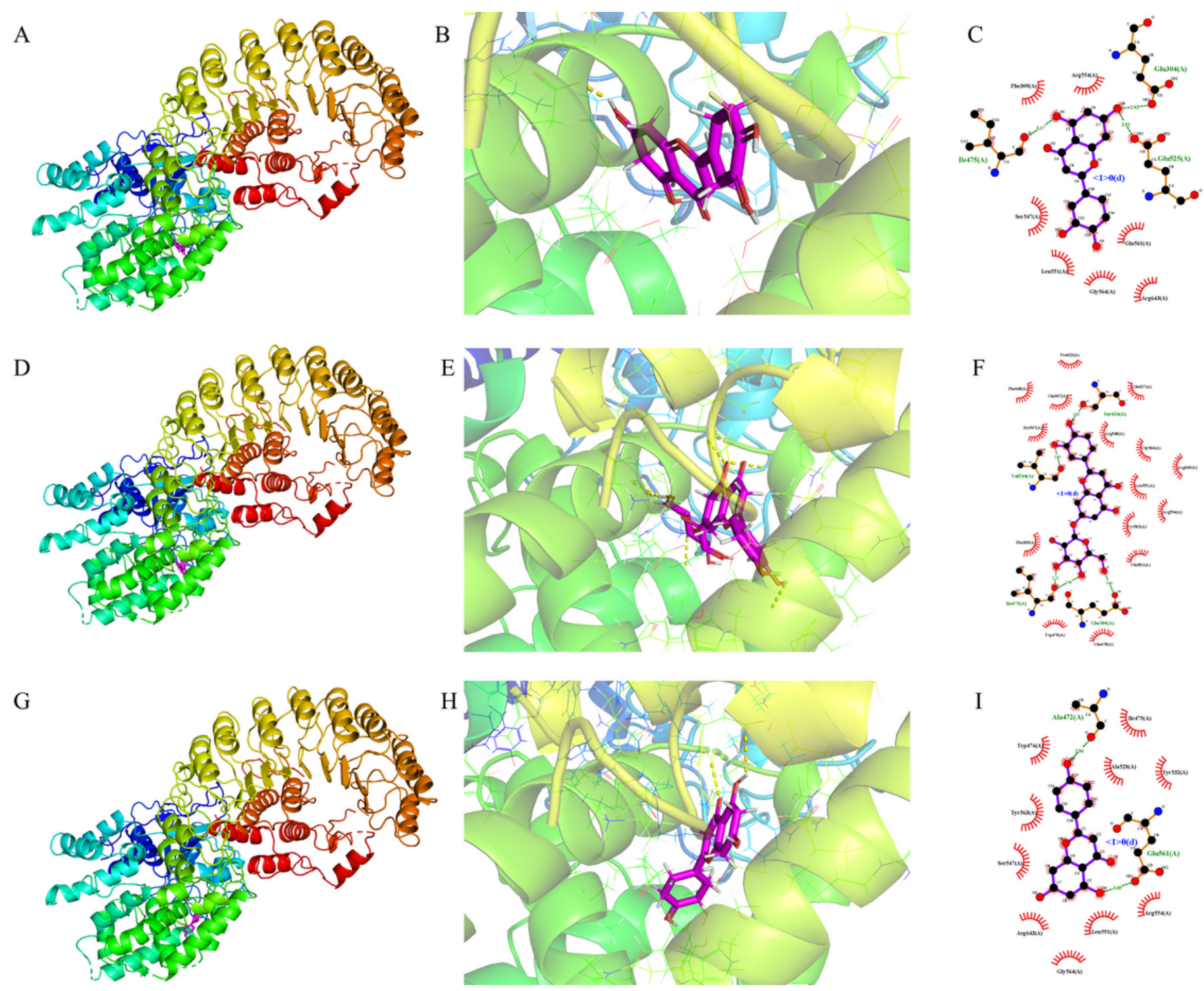

Figure 7

Molecular docking analysis of luteolin, luteoloside and apigenin interacted with NLRP3. A,D and G show that luteolin, luteoloside and apigenin insert into NLRP3. B,E and $\mathrm{H}$ enlarge the interacted structures of NLRP3 and ligands. C,F,I show the detailed interacted sites between TLR4 and ligands. 

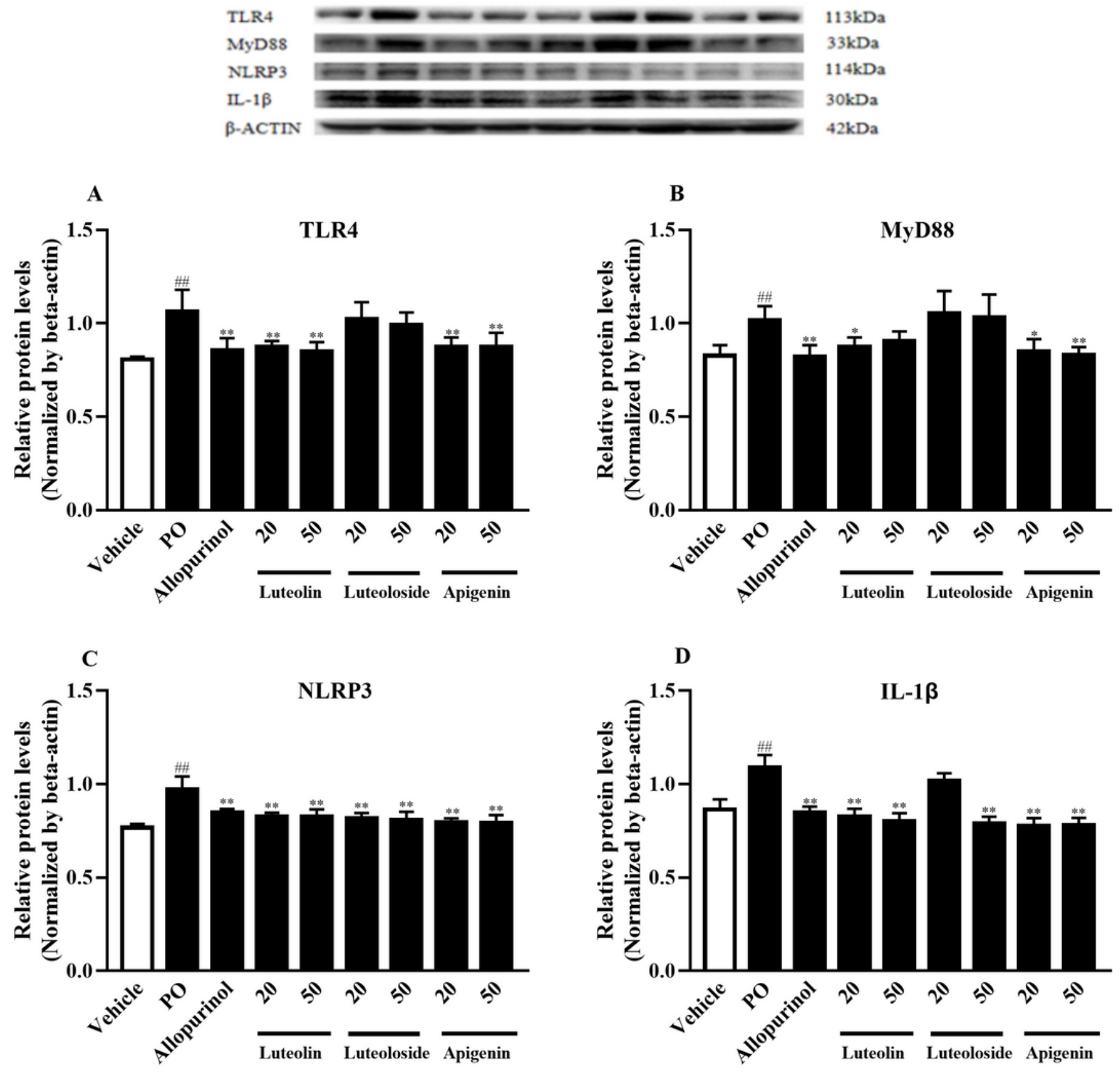

Figure 8

The effects of luteolin, luteoloside and apigenin on TLR4 (A), MyD88 (B), NLRP3 (C) and IL-1 $\beta$ (D) in POinduced hyperuricemic mice. \#\#p $<0.01$ versus the Control-vehicle group. ${ }^{*} p<0.05$ and ${ }^{\star \star} p<0.01$ versus the PO-vehicle group. 


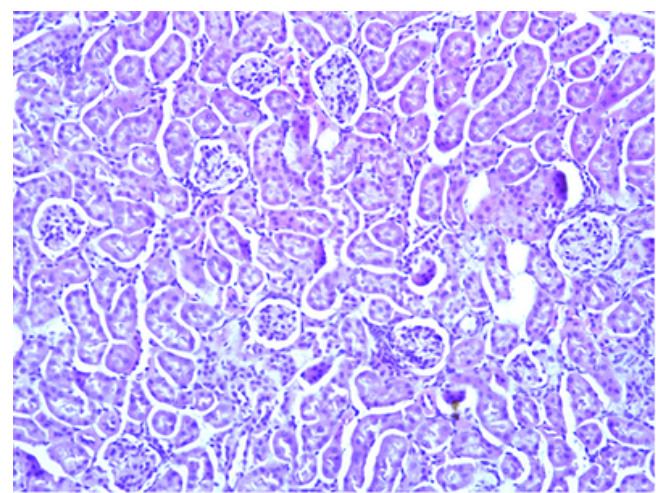

Control-Vehicle

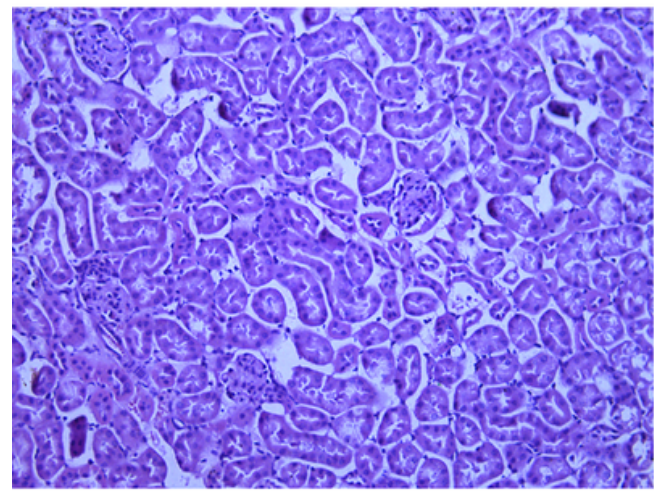

PO-luteolin 20

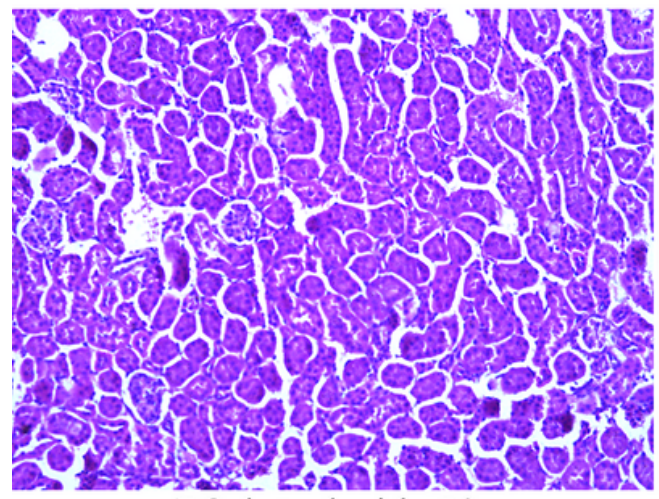

PO-luteoloside 50

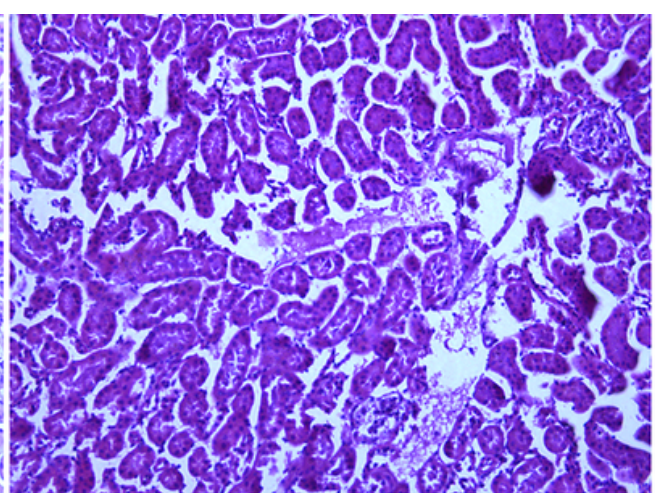

PO-Vehicle

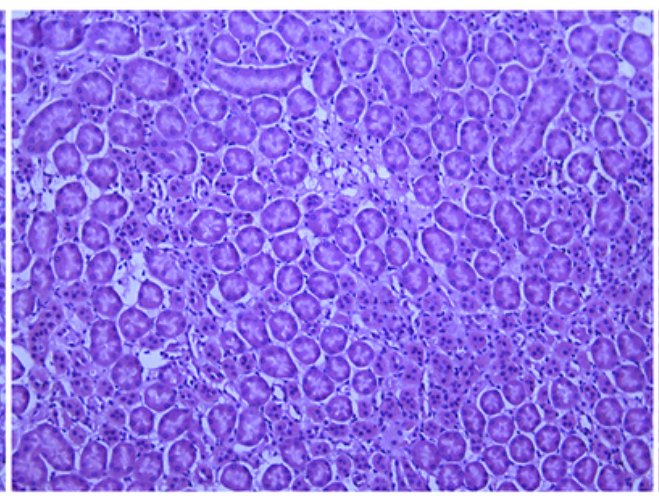

PO-luteolin 50

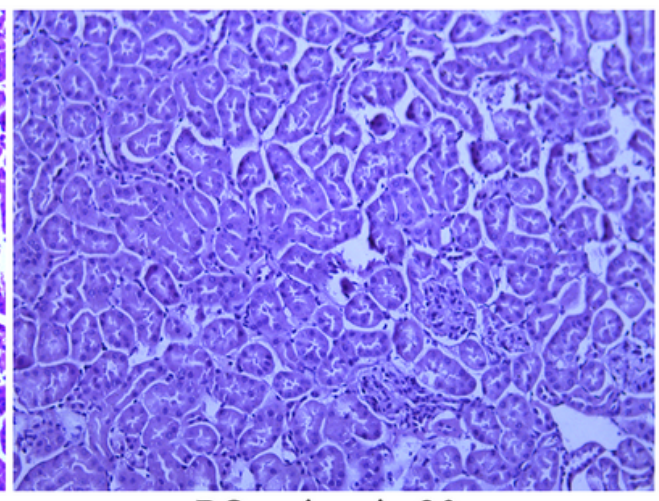

PO-apigenin 20

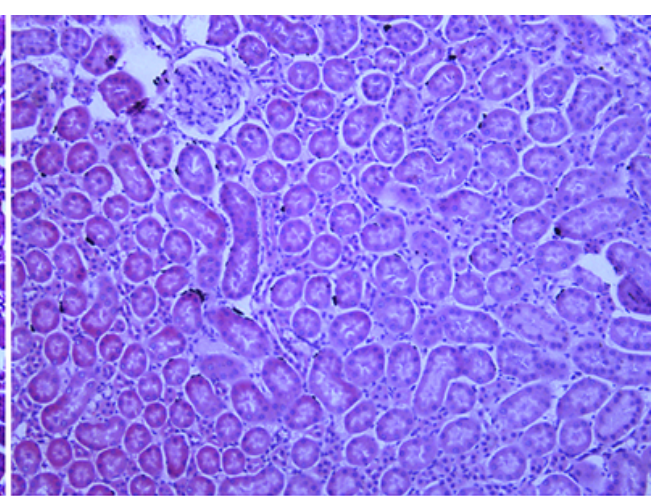

PO-Allopurinol

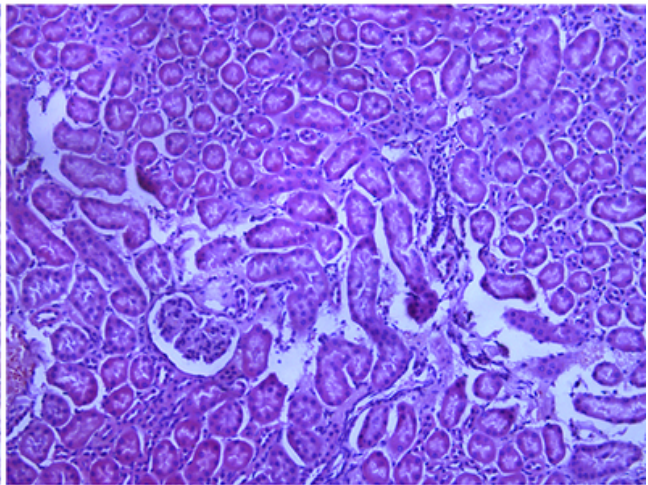

PO-luteoloside 20

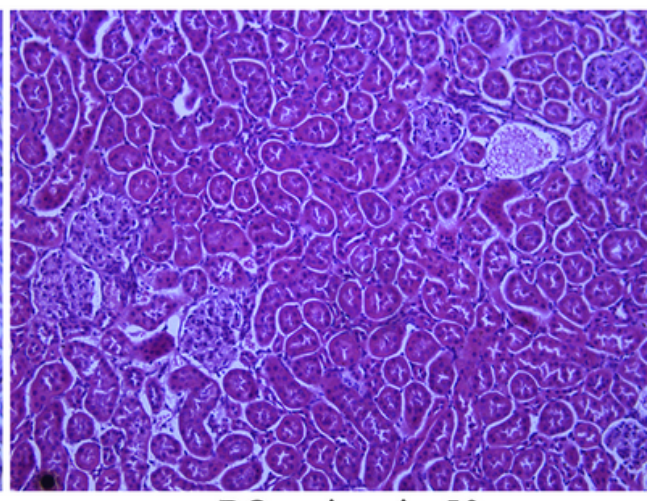

PO-apigenin 50

\section{Figure 9}

The effects of luteolin, luteoloside and apigenin on renal morphology in PO-induced hyperuricemic mice. 